\title{
Ranibizumab and the eye
}

\author{
Jason Noble MD, Varun Chaudhary MD
}

\section{Ranibizumab is the current standard of care for most types of wet age- related macular degeneration}

Ranibizumab is a recombinant, monoclonal antibody fragment that inhibits vascular endothelial growth factor (known as a VEGF-A inhibitor). ${ }^{1} \mathrm{Be}$ cause it costs about 10 times more than bevacizumab, ${ }^{2}$ an anti-VEGF agent approved for intravenous use in metastatic colon cancer, ophthalmologists may choose off-label use of the latter. A recent randomized controlled trial suggested that bevacizumab is safe and effective when used to treat wet agerelated macular degeneration. ${ }^{3}$ A large noninferiority trial comparing these two agents is underway. Anti-VEGF agents have also been shown to produce superior visual outcomes in retinal vein occlusion and diabetic macular edema. ${ }^{46}$
Most patients given ranibizumab still have baseline visual acuity at two years

The safety and efficacy of ranibizumab have been investigated in several recent large, randomized controlled trials. Although the wet form of age-related macular degeneration may result in severe, profound loss of vision if left untreated, more than $90 \%$ of patients who receive monthly intraocular injections of the drug still have baseline visual acuity at two years; $30 \%-40 \%$ have clinically significant improvement in vision at one year, with $40 \%$ of these patients achieving greater than $6 / 12$ acuity. ${ }^{7-9}$

\section{Ranibizumab is delivered by injection into the vitreous cavity}

The original trials used monthly dosing, but smaller studies have suggested that less frequent injections may yield similar results. ${ }^{8,10}$ One approach entails a loading dose of three successive monthly injections followed by careful extension of treatment intervals and close monitoring. If active disease is detected during follow-up, treatment may need to be repeated.

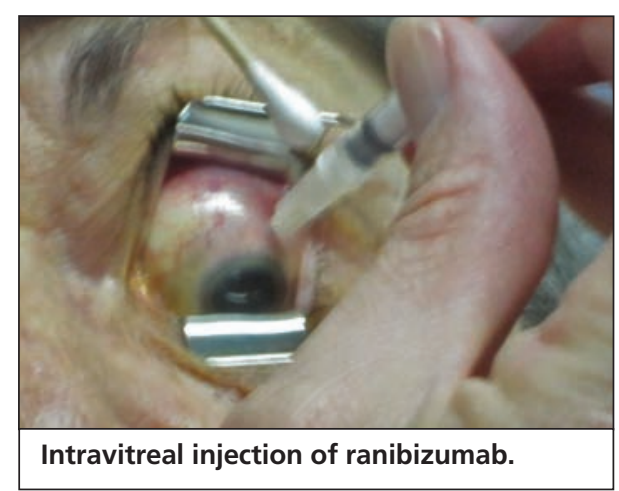

CMAJ invites submissions to "Five things to know about ..." Submit manuscripts online at http://mc.manuscriptcentral.com/cmaj

Patients who have blurred vision, pain and red eye after ranibizumab injection should be referred for urgent ophthalmic evaluation

Adverse ocular effects after intravitreal injection of ranibizumab include irritation, subconjunctival hemorrhage and transient increased intraocular pressure. More serious adverse effects, such as uveitis, endophthalmitis, retinal tears or detachment, and traumatic cataract, are uncommon $(<1.3 \%$ at two years $) .{ }^{9}$

Systemic adverse effects after ranibizumab injection are rare

Several large studies have shown that treatment with ranibizumab is not associated with systemic adverse events. ${ }^{7,9}$ Early concerns about increased risk of thromboembolic events ${ }^{11}$ have not been corroborated by larger studies. ${ }^{12}$ The risk of thromboembolic events continues to be studied through postmarketing surveillance., ${ }^{9,11}$

For references, please see Appendix 1, available at www.cmaj.ca/cgi/content/full /cmaj.090574/DC1

Competing interests: None declared.

This article has been peer reviewed.

Affiliations: From the Department of Ophthalmology and Vision Sciences (Noble), University of Toronto, Toronto, Ont.; and the Department of Ophthalmology (Chaudhary),

McMaster University, Hamilton, Ont.

Correspondence to: Dr. Jason Noble, jason.noble@utoronto.ca

CMAJ 2011. DOI:10.1503/cmaj.090574 